\title{
¿Quién es Cressida? \\ Fidelidad y drama en la identidad personal
}

\author{
Who is Cressida? \\ Fidelity and drama in personal identity
}

Ana Álvarez GARRIDO

Universidad Complutense de Madrid

Recibido: 27/09/2009

Aceptado: 21/01/2010

\section{Resumen}

Partiendo de un pasaje de una obra de Shakespeare, se revisará el papel de la fidelidad en la configuración de la identidad personal. El artículo se centra en dos tendencias principales en la concepción de la misma, enraizadas en la comprensión narrativa del yo: la fidelidad como permanencia frente al cambio y la fidelidad como apertura y avance hacia aquello que hace ser, que da unidad y sentido. Pero el yo se descubre en ambos casos dividido, necesitado de narrar para ser, luchando con el tiempo, ya se presente como amenaza o como obstáculo para ser uno y distinto. La alternativa que aquí se propone consiste en una fidelidad como retorno a lo esencial, donde el ser y la unidad del yo permanecen, en tanto que éste se abre a la novedad de aquéllo fundamental. Dicha apertura consiste básicamente en un diálogo, en el cual el yo recibe y entrega lo propio, poniendo en juego su ser en el espacio dramático, actualizando así cada vez el yo, su unidad y su sentido.

Palabras clave: identidad personal, fidelidad, tiempo, narración, diálogo, drama. 


\begin{abstract}
Starting off of a passage of a work of Shakespeare, the roll of fidelity in the configuration of the personal identity will be reviewed. The article is centered in tow main tendencies in the conception of the same one, taken root in the narrative understanding of the self: the fidelity like permanence opposite to change and the fidelity like opening and advance towards what makes be, gives unity and make sense. But the self is discovered in both cases divided, needed to narrate for being, fighting with time, that can appears like threat as well as obstacle to be only one and a different one. The alternative that sets out here lies in a fidelity like return to the essential, where the being and the unity of self remain, whereas he open himself to the newness of that fundamental. This opening consist basically in a dialogue, in which the self receives and gives his own, playing its being in the dramatic space, thus actualizing every time the self, its unity and its sense.
\end{abstract}

Keywords: personal identity, fidelity, time, narration, dialogue, drama.

\title{
1. Introducción
}

Antes de ser conducida prisionera al campamento griego, Cressida le ha prometido a Troilo serle fiel. Escondido, este troyano contempla poco después, cómo aquélla traiciona la palabra dada, sucumbiendo al juego de seducción con uno de los soldados griegos. El amante herido, como enajenado, exclama entonces:

¿Era ella? No, era la Cressida de Diomedes. Si la belleza posee un alma, no es ella;... si hay una ley en la identidad misma, no es ella. ;Oh locura de la lógica, que puede defender el pro y el contra de la misma causa! Autoridad equívoca, que permite a la razón rebelarse sin perderse, y al error abrirse paso sin rebelión de la razón! ¡Es y no es Cressida! En mi alma se libra un combate de tan extraña naturaleza, que un ser idéntico se divide en dos personas, más separadas la una de la otra que el cielo está de la tierra; y sin embargo, el espacio inmenso comprendido entre estas dos divisiones no admite abertura lo bastante amplia para que se pueda introducir por ella un punto tan sutil como uno de los hilos de la tela rota de Ariadna. ;Certeza, oh certeza fuerte como las puertas de Plutón! Cressida me pertenece, encadenada a mí por los lazos del cielo. ¡Y certeza, oh, certeza fuerte como el cielo mismo! Los lazos del cielo están deshechos, desatados y disueltos; y con otro nudo, liado por sus cinco dedos, ha atado a Diomedes los despojos de su fe, los destellos de su amor, los fragmentos, los trozos, las porciones, las reliquias grasientas de su fidelidad roídas hasta los huesos. ${ }^{1}$

1 Shakespeare, W.: Obras completas II, trad. Luis Astrana Marín, Madrid, Aguilar, 2003. 
¿Era ella? ¿Era la misma? Troilo duda porque la que era, ahora es y no es ella. ¿Es posible que sean dos?, y si no es posible, ¿quién es Cressida? A partir de los personajes principales de este drama de Shakespeare, nos proponemos revisar el papel de la fidelidad en la configuración de la identidad personal, para mostrar, en lo posible, una vía más fiable y más original hacia el yo, en tanto que sea capaz de conducirnos al origen, a las "fuentes del yo"2. Sea lo que sea el yo, se presenta siempre como lo que aún no soy del todo, lo no-idéntico, atravesado por una diferencia que lo sitúa siempre entre un ser y un no-ser-todavía, un estar de camino. ${ }^{3}$

Para esclarecer qué tipo de fidelidad requieren la unidad y el ser personales, habrá que profundizar en el problema de la dirección de la acción, del lugar al que se tiende para alcanzar la unidad, que se concentra paradójicamente en la cuestión del sentido, como un cierto origen al que el yo fielmente retorna. ¿Cómo se puede regresar a lo que aún no se ha llegado? ¿Qué tipo de sentido es aquél que se encuentra en el origen? La fidelidad a sí mismo se sitúa precisamente en el filo de la paradoja de ser un yo que tiene que avanzar hacia el futuro para encontrar la forma adecuada a sí mismo, forma en la que por tanto se conserva, donde futuro y adecuación de sí se contradicen, por el retorno que toda permanencia supone. Por eso, adónde se regresa y quién es el que regresa sólo pueden descubrirse a la vez.

Desenmascarar será entonces lo más urgente, pues tanto la fidelidad como el yo, son asiduos al disfraz. Si se habla de fidelidad hay que precisar a qué o a quién, cómo y para qué. Una vez esclarecido el problema, habrá que dejarlos actuar con sus máscaras y ver cuál de ellas corresponde al auténtico rostro, o mejor, con cuál de ellas puede mostrarse Cressida, si es que ésta existe y sólo es una. Será entonces cuando el punto de vista narrativo y el dramático de la identidad personal tendrán

\footnotetext{
2 Es uno de los títulos más conocidos de Charles Taylor, a la vez que una de nuestras principales referencias: Fuentes del yo. La Construcción de la Identidad Moderna, Barcelona, Paidós, 1989/1996. En adelante se citará FY y la página.

3 Esta es la diferencia principal con la que tropieza el problema de la identidad personal. Por eso la mayoría de los autores lo plantean de un modo u otro como un problema de adecuación del yo a sí mismo. Cf. Blondel, M.: La Acción, Madrid, B.A.C., 1893/1996, p. 386. Cf. FY, p. 63: "La cuestión de nuestra condición jamás se agota en lo que somos porque siempre estamos cambiando, deviniendo"; la distinción entre identidad idem e ipse procede de esa diferencia (cf. Ricoeur, P.: Sí mismo como otro, Madrid, Siglo XXI, 1990/1996. En adelante MO); innumerables son las referencias en Balthasar, H.U.v.: Teológica 1, Madrid, Encuentro, 1985/1997 y Teodramática 1 y 2, Madrid, Encuentro, 1973/1990 y 1976/1992 (estos títulos se citarán del siguiente modo: Tl 1, Td 1 y Td 2); Cf. Guardini, R.: La aceptación de sí mismo, trad. J. M. Valverde, Madrid, Ediciones Cristiandad, 1960/1970, p. 20): "¿De qué modo yo soy yo mismo?... Yo no soy por esencia, sino que me estoy "dando"”; y también "ser-yo significa precisamente tener un camino que lleve desde el Yo de la situación inicial al de la plenitud" (op. cit., p. 31). Entre la abundante literatura teatral, las obras más próximas a una consideración filosófica de la cuestión son Abirached, R.: La crisis del personaje moderno, Madrid, Publicaciones de la asociación de directores de escena, 1978/1994; Szondi, P.: Teoría del drama moderno. Tentativa sobre lo trágico, Barcelona, Destino, (1956/1961)/1994; y Pavis, P.: Diccionario de teatro, Barcelona, Paidós, 1996/1998.
} 
oportunidad de carearse sin máscaras ajenas. Nuestro objetivo se verá cumplido si logramos encontrar, apoyados en nuestros autores, una fidelidad que, más que un punto de llegada a la identidad consigo mismo, se muestre como camino hacia una forma dramática del yo. Buscaremos entonces la naturaleza dramática de la fidelidad y su relación con la identidad personal.

Sin embargo, antes de comenzar a desgranar el problema conviene señalar que la cuestión de la identidad personal se encuentra ligada a la de su certeza: “¿Es verdad que este soy yo?". Quien reflexiona acerca de sí mismo, se expone a la sospecha, pero el fundamento de esta certeza no puede encontrarse exclusivamente en la conciencia del sujeto, por el contrario, necesitará atravesar el suelo "incierto" de la confianza y en concreto confianza en el otro. ${ }^{4}$ Así, el paso al escenario se ha dado aquí sobre el convencimiento de que cuestiones como la del yo, sólo en diálogo se pueden conocer, es decir, en el intercambio y la puesta en juego en el espacio interpersonal. 5 Por eso, la realidad profunda de los conceptos que queremos explorar requiere enfrentar el drama de la vida, adentrarse como Cressida en el campamento aqueo, exponer la propia existencia y poner a prueba su sentido; porque hay certezas que son sobre todo fruto de la acción, son dramáticas ${ }^{6}$.

Una razón más para volvernos hacia el drama es que nos brinda un lenguaje común. Así, cuando Troilo desespera a causa de unos lazos que se han deshecho y anudado a otro lugar, sabemos lo que la imagen significa: un vínculo que se extendía entre los amantes y que, al cambiar de dirección, se perdió lo que ponía tensión en la forma que hacía reconocible a Cressida, vínculo fuerte "como fuertes son los lazos del cielo", hilo de vida que teje y desteje la unidad y el ser de Cressida. Por ello, si "los lazos del cielo están deshechos, desatados y disueltos", ¿qué salvará ya la distancia entre las dos Cressidas, "más separadas la una de la otra que el cielo lo

\footnotetext{
4 Sobre las relaciones entre identidad personal y diálogo, certeza y confianza, cf. Marcel, G.: Ser y tener, pp. 96-100, 116. También acerca de la conciencia discursiva y su vínculo inevitable con la sospecha se puede ver la obra de Lyotard, J-F.: La condición postmoderna, Madrid, Cátedra, 1984/2004, pp. $60,75,76$.

5 "Uno es un yo sólo entre otros yoes... Es esta situación original la que proporciona sentido a nuestro concepto de identidad al ofrecer respuesta a la pregunta '¿quién soy yo?' mediante una definición del lugar desde donde hablo y a quién hablo" (FY, pp. 51-52). Al "intercambio" propio de la visión, ya en cierto modo dialógica, de Taylor y de Ricoeur, nosotros añadimos la necesidad de "poner en juego", de dramatizar para devenir yo mismo. La apertura a la novedad de la acción y del otro no está tan clara en estos autores: cf. Álvarez, A.: Identidad personal y donación: la configuración del yo en la acción dramática, UCM, 2008. Para lo dramático se ha tomado como referencia principalmente a Balthasar, pero también a Blondel y a pensadores del movimiento dialogal, como Martin Buber y Gabriel Marcel, así como del ámbito teatral: Robert Abirached, Peter Szondi y Patrice Pavis (Cf. Referencias de este artículo).

6 "El adjetivo "dramático" no expresa en lo que sigue ninguna cualidad... significa exclusivamente "relativo al drama" ("diálogo dramático" significará, pues, diálogo dentro del drama)" Dramático se considerará aquí también, por tanto, todo lo que participa de las características esenciales del teatro (Szondi, P.: Teoría del drama moderno, pp. 16; 17-22).
} 
está de la tierra"?, ¿cómo se anudarán la unidad y el ser?, ¿sobre qué se levantará una certeza, "fuerte como las torres de Plutón y como el cielo mismo"? La fidelidad que buscamos tendría que poder extender lazos capaces de alcanzar la diferencia (o el sentido) y la unidad (o el yo) en un mismo movimiento.

\section{El problema de la diferencia}

Troilo expone la locura de tener que admitir lo imposible: que a pesar de la enorme diferencia entre dos personas, "más separada la una de la otra que el cielo está de la tierra", éstas sean la misma. Este es el peculiar experimento mental al que se ve sometido el joven, que ahora funciona para nosotros como "motor de intuición". 7 A diferencia del clásico experimento mental, la situación no sólo es lógicamente posible sino que tiene verosimilitud. Lo que otros toman por expresiones de la locura que el arte puede permitirse, una lectura atenta es capaz de descubrir en ellas la mirada profunda de su autor acerca de lo que significa ser uno y distinto, así como del sostén o fundamento de su ser y su certeza. Esa profundidad es la que queremos sacar a la superficie.

Ciñéndonos al texto, aparece en primer lugar una duda acerca del ser de una persona, “¿era o no era ella?”, duda que a simple vista procede de la falta de uni$d a d$, ante el hecho evidente de que algo no puede ser esto $y$ lo otro a la vez, sino sólo una sola cosa, esto $o$ aquello. En el caso de que la fractura sea posible sin error lógico (porque las dos Cressidas son "verdaderas"), la sospecha se extendería a todo lo que hasta ahora se juzgaba como verdadero. Por eso Troilo se preguntará no sólo por el ser de Cressida, sino también por la ley y el sentido por los que se habría de juzgar entonces la identidad de los seres. "Si hay una ley en la identidad misma, no es ella", lo cual indica que si ella era realmente Cressida, la identidad es entonces un concepto sin definición, sin ley, sin expresión en el mundo real y, por tanto, sin importancia para nadie. Nosotros queremos adentrarnos en esta distancia o diferencia mortal, capaz de horadar la certeza acerca del ser y del sentido, para encontrar alguna pista sobre su propio antídoto y llegar así a la unidad, al yo.

Cualquiera que sea la causa de dicha diferencia, se llega siempre a la misma conclusión: el yo que designamos con un nombre no es idéntico a sí mismo, sino

\footnotetext{
7 Los thought-experiments que proliferan en el debate anglosajón sobre filosofía de la mente, consisten en "extravagantes experimentos de pensamiento, por ejemplo una misma conciencia habitando cuerpos diferentes, o dos conciencias compartiendo el mismo, o cuerpos intercambiando conciencias" (FY, p. 188). Para una revisión crítica de su amplio espectro cf. Rodríguez González, M.: "El laberinto de la identidad personal", El problema de la identidad personal. Más que fragmentos, Madrid, Biblioteca Nueva, 2003, pp. 33-112. Funcionan como "motores de intuición" porque buscan un criterio constitutivo de identidad personal a través de casos que, a pesar de ser inverosímiles, son lógicamente posibles (op. cit., p. 44-47).
} 
que le alcanzan los cambios con el paso del tiempo, elige unas formas de actuar, y entre lo que aparece y el que aparece siempre se revela una distancia, como aquélla infranqueable entre el actor y su personaje. Ante este problema, las soluciones se dividen básicamente entre los que afirman que sí hay identidad personal a pesar del cambio y los que lo niegan. Sin detenernos en las variaciones a las que se acoge cada una de estas posturas, podemos distinguir dentro del primer gran grupo, la idea común de que la identidad requiere algún tipo de unidad personal, unidad ligada a su vez a una noción de constancia y fiabilidad, confianza en que a pesar de los cambios, bajo esas apariencias permanece alguien y no meros efectos de conciencia. ${ }^{8}$ Los que así piensan buscarán aquello que une lo diferente, el vínculo por el cual se puede hablar en cada caso de pertenencia de lo que aparece al mismo yo y de permanencia del yo en las apariencias cambiantes. Sin espacio ni motivos suficientes para una justificación ${ }^{9}$ de la opción por este primer grupo, nos dedicaremos directamente a investigar el vínculo capaz de alcanzar esa unidad personal.

Charles Taylor y Paul Ricoeur aportarán cada uno un modo de unidad como solución al problema de la diferencia. Desde otras perspectivas, otros autores buscarán básicamente lo mismo. Pero unos enfoques y otros se remontan a una diferencia previa, más fundamental que la que se pone en evidencia con el paso del tiempo: aquello "sumamente importante"10 que orienta la acción, que marca el sentido del movimiento en el cual se encontraría la unidad personal; es lo esencial para ser él y sin ello se encuentra distanciado de sí, fragmentado. Por el hecho de que los mismos, que desde diferentes perspectivas proponen la diferencia como el problema principal, se remontan a su vez al problema del sentido, y por el hecho no menos significativo de que nuestro pasaje lo sitúa también en el centro de la "locura de la lógica" que padece Troilo, vamos a tratar entonces la cuestión del sentido, como aquello en base a lo cual se puede aspirar a una unidad personal.

\footnotetext{
8 Para Parfit, la identidad personal es una mera creencia, bajo la que explicamos una serie de relaciones de continuidad física y/o psicológica (Parfit. D.: Reasons and Persons, Oxford, Clarendon Press, 1984, pp. 217-218, 281). Los narrativistas sostienen en general una postura intermedia y algo ambigua al respecto: el yo no tendría realidad sino como relato. Para una discusión acerca de lo "ficticio y lo verdadero" de una identidad personal concebida de forma "autobiográfica", cf. Velleman, J. D.: "The Self as Narrator", Self to Self, Nueva York, Cambridge University Press, 2006, pp. 203-223.

9 Para una comprensión del giro narrativista ante el reduccionismo imperante de la filosofía analítica en lo que respecta a la comprensión del yo, cf. Rodríguez González, M.: "La identidad narrativa", El problema de la identidad personal, p. 113 ss.
}

10 FY, p. 43. 


\section{Fidelidad como retorno a la unidad de sí}

La unidad o mantenimiento de sí, de Cressida, resultaría de la conservación de los lazos en la dirección marcada por lo más importante, hacia lo cual se tiende para adquirir sustancia o para ser yo. A dicho mantenimiento, Taylor y Ricoeur entre otros, lo llaman fidelidad. Sin embargo, ser fiel se traduce de manera distinta según cuál sea esa dirección.

\subsection{Fidelidad y unidad narrativa en la identidad personal}

De diferentes formas aluden estos autores a la fidelidad como factor de permanencia, consistente en el mantenimiento de la dirección o de la posición del sujeto respecto a un fin, del cual que depende la "sustancia" del yo, no en cuanto sustrato ${ }^{11}$, sino precisamente como relación de unidad y distancia con él. El movimiento del yo hacia lo valioso en sí, aparece en cualquier caso como un camino de unidad, en el que el yo cambiante busca el vínculo con aquella diferencia que orienta y permanece en su valor: el bien 12 o principalmente el otro en el caso de Ricoeur ${ }^{13}$, permitiendo así a la persona permanecer a través del tiempo.

Ambas unidades (con el sentido y consigo mismo) son como los dos bordes del mismo camino de unidad, exigente de una fidelidad apoyada paradójicamente en la diferencia: la referencia o sentido, el polo de la relación que es diferente a mí. La relación de unidad y distancia que exige entonces la sustancia del yo, se descubre problemática, pues ¿dónde está el límite de la unidad con dicho fin?, ¿no será la distancia con ello siempre un lastre, algo que me impida ser "totalmente" yo?, y ¿no se "pierde" lo propio en la apertura a esa diferencia fundamental? Pues tras la fidelidad a lo importante, el yo pierde su antigua posición pero tampoco ha hallado la definitiva, ¿dónde se encuentra lo fundamental de sí mismo entonces?, ¿dónde puede depositar la garantía de su unidad y con ella de su ser personal? La diferencia es vista en estos casos como un "menos" en el ser, dando lugar a una tensión dialéctica que reclama inevitablemente la estabilidad de una unidad fuera de sospecha, por eso se tiende a

\footnotetext{
11 Como "forma de permanencia en el tiempo irreductible a la determinación de un sustrato". Se trata de una forma narrativa, correspondiente a la "permanencia del mismo" (cf. MO, p. 112-113). Taylor también considera "el valor, o peso, o sustancia de mi vida, como la cuestión de dónde me "sitúo" o "ubico" en relación al bien, o si estoy en "contacto" con él" (cf. FY, p. 59).

12 Esta idea es el centro de la primera parte del libro, "La identidad y el bien", concretamente del capítulo "El yo en el espacio moral", en FY, pp. 41- 68.

13 Ser fiel a la expectativa del otro que cuenta conmigo, da lugar a un tipo de permanencia en el tiempo llamada identidad ipse. Sólo gracias al otro es posible la vida buena y el mantenimiento de la promesa que nos hace permanecer nosotros mismos (MO, pp. 120 y 168).
} 
un fundamento absoluto, que aunque se trata de evitar, reaparece como trasfondo de la reflexión. Si bien la unidad no se puede lograr de facto -pues siempre el fin y yo, el otro y yo, seremos distintos-, se buscará al menos una forma de recogerla: la narración de sí14. En ambos autores la imagen narrativa de mí mismo contiene ese acercamiento que da valor a mi vida, donde se reconoce la posición personal y en ella los dos extremos de aquellos lazos vinculantes: el yo y la diferencia que marca el sentido.

Por tanto, al narrar se logra recoger los tres elementos problemáticos de la identidad vistos hasta ahora: el sentido - por el cual el yo puede orientarse y permanecer-, la unidad -por la cual el yo se adecúa a sí mismo tras los cambios-y el ser -como aquello necesario para considerar al yo algo más que fenómenos sin hondura, sin significado, algo más que apariencia. 15

\subsection{Con el tiempo en contra}

Ricoeur viene a recoger la postura básica general respecto al tiempo, de los que consideran la identidad de forma narrativa:

El tiempo es aquí factor de desemejanza, de separación, de diferencia. Por ello, la amenaza que representa para la identidad sólo queda enteramente conjurada si se puede plantear, en la base de la similitud y de la continuidad ininterrumpida del cambio, un principio de permanencia en el tiempo... Toda la problemática de la identidad personal va a girar en torno a esta búsqueda. ${ }^{16}$

$14 \mathrm{El} \mathrm{rechazo} \mathrm{del} \mathrm{fundamento} \mathrm{absoluto} \mathrm{junto} \mathrm{al} \mathrm{acuse} \mathrm{de} \mathrm{su} \mathrm{carencia,} \mathrm{es} \mathrm{una} \mathrm{constante} \mathrm{al} \mathrm{comienzo} \mathrm{de}$ Sí mismo como otro, y esto parece, a la luz del conjunto, algo más que una paradoja. "La diversidad de sentido que ahuyenta la ambición de fundamento último característica de las filosofías del Cogito" (p. XXXIV) se combina con la búsqueda de una certeza similar por medio de "la triple dialéctica de la reflexión y del análisis, de la ipseidad y de la mismidad, del sí y del otro" (p. XXXV), que si bien es la certeza propia de la hermenéutica, de la atestación de sí, puesta en manos del testigo, siempre adolece de "una fragilidad específica a la que se añade la vulnerabilidad de un discurso consciente de su falta de fundamento. Esta falta de fundamento se expresará en la amenaza permanente de la sospecha" (p. XXXVI), ante un "crédito sin garantía" (p. XXXVII). Según Ricoeur, para tener una identidad personal, no basta pues con creer en la palabra del otro, hace falta narrar, recoger lo dialéctico en una unidad. Sobre la dialéctica como forma de conocimiento que tiende hacia un punto de vista total, cf. Tl 1, p. 184.

${ }^{15}$ ¿Habrá algo entonces más que un texto o una composición narrada de partes en esta identidad? Esa es la duda principal ante expresiones como: "El sujeto de la ética no es otro que aquel a quien el relato asigna una identidad narrativa" o "la noción de unidad narrativa hace hincapié en la composición entre intenciones, causas y causalidades, que encontramos en todo relato" (MO, p. 184). Sobre esta duda en concreto: cf. Gergen, K. J.: El yo saturado. Dilemas de identidad en el mundo contemporáneo, trad. L. Wolfson, Barcelona, Paidós, 1991/1992, pp. 26, 144, 224.

$16 \mathrm{MO}$, pp. 111-112. 
Y frente al tiempo así concebido, el antídoto sería la fidelidad a la dirección fundamental de la vida. Por eso, la relación entre identidad narrativa y tiempo también se comprende solamente sobre un fondo de sentido último ${ }^{17}$. En realidad, como veremos, de cuál sea ese sentido dependerá la forma de concebir el tiempo.

No importa si dicha diferencia, fuente de sentido (dirección y significado), se presenta como amenaza o como promesa de una auténtica identidad, se tratará en cualquier caso de lo distinto. Así planteada, la relación resulta dialéctica, fundamentalmente por el requisito de superar la diferencia para poder ser definitivamente yo. La temporalidad en la que se desarrolla la vida, significará desemejanza en ambos casos, falta de identidad, pues siempre nos conduce hacia un no-yo. Mientras la diferencia que marca el sentido consista en un no-ser, el tiempo irá en contra, pues tanto si el individuo trata de "detenerse" en lo que hoy es, como si "corre" hacia la meta, el tiempo le resulta un impedimento para ser él mismo.

Consideramos la concepción que tiene Ricoeur de la fidelidad como un ejemplo del primer caso:

El cumplimiento de la promesa...parece constituir un desafío al tiempo, una negación del cambio: aunque cambie mi deseo, aunque yo cambie de opinión, de inclinación, "me mantendré" (...) "El acto de la promesa transforma esta discordia en frágil concordia: es cierto que "puedo probar todo", pero "jaquí me detengo!" (op. cit., p. 119, 171).

Sin poner en cuestión el valor de la decisión de mantenerse allí donde el otro pueda encontrarle, se quiere hacer notar la sutil inclinación hacia el pasado, pues "la trayectoria seguida hasta ahora", "la posición en la que me encontraba", etc. son las principales referencias para una fidelidad que concibe el tiempo como amenaza (op. cit. p. 111). Por otro lado, aunque también se contempla la necesidad de abrirse al otro y su fidelidad parezca entonces mirar hacia delante ${ }^{18}$, el cambio seguirá siendo algo a articular por medio de la narrativa, pues la diferencia que sobreviene con el cambio, supone en cualquier caso una amenaza para la unidad personal. No

\footnotetext{
17 La cuestión del sentido de la vida y por tanto el del tiempo, se repite en nuestros autores: "¿A qué aspira mi vida?, ¿posee peso y sustancia, o se me escapa en nada, en algo insustancial? Otra manera de plantearse la cuestión es si nuestra vida posee unidad, o si un día sigue al siguiente sin propósito ni sentido: si el pasado cae en una especie de nada que no es preludio, ni vaticinio, ni apertura, ni comienzo de nada" (FY, p. 59); Cf. Blondel, M.: La Acción, p. 3. En todos ellos se plantea una suerte de horizonte moral sobre el que se narra o actúa el yo.

18 Una fidelidad al servicio de la unidad personal, oscilará entre el cierre de sí ante el cambio y la apertura de sí al bien o al otro. Sobre la necesaria posesión y desposesión de sí cf. MO, 171-172, sobre la solicitud, op. cit., p. 192, sobre apertura de sí y función descubridora, op. cit., p. 377. Marcel habla de la fidelidad como disponibilidad al querer del otro (cf. op. cit., pp. 292-293). Balthasar se expresa en términos de autoposesión e indiferencia (cf. Td 2, pp. 191-223), pero la tensión entre lo propio y ajeno no es dialéctica, sino dialógica. Lo que distingue a Ricoeur de Marcel o de Balthasar es la tensión dialéctica (y no dialógica) entre estos dos movimientos.
} 
es casualidad que una de las funciones más repetidas de la narración de sí, sea la articulación del cambio con la permanencia, pues la pregunta ¿quién soy? sigue exigiendo una referencia a este yo actual, a su fin y a la unidad de ambos, unidad que el cumplimiento de la promesa no puede garantizar por sí mismo, ésta sólo podría proceder del relato. ${ }^{19} \mathrm{Si}$ bien la fidelidad se plantea desde la postura narrativista como desafío al cambio que sobreviene con el tiempo, ésta no logra por sí misma la unidad perdida, hace falta narrar.

En cambio, bajo la perspectiva de Taylor, se diría que el yo sobre todo ha de avanzar hacia lo valioso, aquello sumamente importante por lo que esencialmente se define. El tiempo aquí se interpone entre el yo y el fin deseado y resulta también algo a superar. Podría decirse de este presente, que tiende a ser visto como un obstáculo, pues el fin, la unidad y el ser, no se pueden dar "ahora", sino más allá, en todo caso en el futuro.

Y mientras proyecto mi vida hacia delante y avalo la dirección que llevo o le doy una nueva, proyecto una futura narración, no sólo un estado del futuro momentáneo, sino la inclinación para toda la vida que me espera... como si estuviera encaminada en la dirección hacia lo que aún no soy. 20

Stephen Crites, ha señalado esta dificultad de la narrativa para situarse entre el pasado y el futuro, entre la conservación y la apertura de sí. Poniéndose en el lugar del "hombre más infeliz" descrito por Kierkegaard, muestra la tendencia de la narración aplicada a la propia vida, a detenerse en el pasado y a anticipar el futuro, precipitando un deslizamiento del yo hacia la ausencia de sí mismo.21

\footnotetext{
19 "Este nuevo modo de oponer la mismidad del carácter al mantenimiento de sí mismo en la promesa abre un intervalo de sentido que hay que llenar... Ahora bien, este "punto medio" es el que viene a ocupar... la noción de identidad narrativa" (MO, p. 120). "También nuestras vidas existen en ese espacio de interrogantes al que sólo puede responder una narrativa coherente". (FY, p. 64).

20 FY, p. 65. Es cierto que "se requiere mirar tanto hacia atrás como hacia delante" (op. cit. p. 64), pero en tanto que lo que me mueve o me atrae se encuentra al final del recorrido, lo presente ha de entenderse sobre todo como un tránsito.

21 Crites, S.: "Storytime: Recollecting the Past and Projecting the Future", en Sarbin, Th. R. (ed.): Narrative Psychology: The Storied Nature of Human Conduct, Nueva York, Praeger, 1986, pp. 152173. "Constantemente espera algo que debería ser recordado; su esperanza es constantemente decepcionada... porque ya es pasado..., ya ha sido experimentada o debería haber sido experimentada y ha pasado a ser recuerdo. Por otro lado, constantemente recuerda lo que debería esperar; porque ya ha anticipado el futuro en el pensamiento, ya lo ha experimentado, y recuerda ahora su experiencia, en lugar de esperarla" (Kierkegaard, Den Ulykkeligste, en op. cit., 153).
} 


\title{
3. Fidelidad como retorno a lo esencial
}

\author{
Se puede pasar de largo ante todo lo inesencial; \\ a lo esencial hay que volver eternamente. \\ Ésta es la fidelidad que él merece y que hay que guardarle.
}

Hans Urs von Balthasar

Tras haber explorado las relaciones entre fidelidad, identidad narrativa y tiempo, podemos comenzar esta última parte diciendo que la identidad personal necesita de una fidelidad a sí mismo que haga al yo volver a lo esencial de sí. Pero podemos tropezar fácilmente con una vieja dificultad: la del fundamento absoluto. Si supiéramos qué es el yo, la fidelidad consistiría en no desviarse de esta esencia, si el yo fuese algo, si su fundamento fuese una sola cosa, la unidad, el sentido y el ser de la identidad personal se explicarían a la luz de este fundamento único. Pero si la diferencia resulta vital para ser yo, hay que buscar lo esencial en un espacio relacional en el que sean posibles lo singular y lo común, la diferencia y la unidad simultáneamente, donde lo diferente no se presente como algo a superar. Por otro lado, el tiempo del encuentro con lo esencial, de esta unidad y diferencia, constituye una clave para comprender la fidelidad de forma justa: ¿Qué hacer?, ¿conservar la forma de hoy desafiando al futuro incierto?, ¿o bien perder la forma actual para ganar una venidera más plena? Así, la pregunta por el espacio en el que el yo se configura está ligada a la del tiempo, y ambas cuestiones se encuentran enraizadas en el problema de la diferencia y del sentido. La propuesta de diversos autores, a la cual nos unimos, es la siguiente: la diferencia interpersonal sería la única en la que pueden darse la unidad y diferencia simultáneas, cuyo espacio y tiempo son los propios del diálogo. Lo sumamente importante tiene lugar en el "aquí y ahora" del encuentro entre yo y tú, pero se trata de un presente cuajado de futuro, porque lo que hace del encuentro algo importante y novedoso, es su apertura hacia un más, que es esencialmente futuro. Veamos entonces en qué consiste este futuro del espacio dialogal, en el que la fidelidad, como abandono de la propia posición, es sinónimo de regreso y permanencia.

\subsection{Fidelidad y unidad dialógica}

Ricoeur comprendió que la fidelidad a sí mismo tenía que pasar por la disponibilidad o apertura al otro 22 , sin embargo, en el espacio interpersonal que propone,

22 "La obligación de mantenerse a sí mismo cumpliendo sus promesas corre el riesgo de petrificarse en la rigidez estoica de la simple fidelidad, si no es regada por el deseo de responder a una expectati- 
siempre se necesita la narración para asegurar la unidad, el ser y el sentido del yo. Puesto que en Sí mismo como otro se habla en numerosas ocasiones de diálogo 23 , parece conveniente esclarecer en qué se distingue esencialmente de otro diálogo en el que es posible ser fiel y ser yo, antes de toda forma narrativa. Sin detenernos en este punto, podemos señalar no obstante que la relación dialéctica resulta ajena al auténtico diálogo, porque contrapone a las partes tratando de superar su diferencia $^{24}$. En cambio, los que dialogan, no lo hacen con el fin de superar lo que les diferencia, sino fundamentalmente para dar lo propio al otro, en libertad, motivo que sólo se retrae en última instancia a un porque sí último, un fundamento peculiar por el hecho de carecer de todo otro fundamento. Si no fuese así, el diálogo terminaría cuando se lograse el fin para el que es medio; muy por el contrario, la realidad del espacio dialógico es absoluta, al estar caracterizada por la ausencia de motivos ajenos a la comunicación misma: ni lo interno (la intimidad del sujeto) ni lo externo (las circunstancias) son determinantes, sino "la libertad y el vínculo, la voluntad y la decisión... Cuanto se hallase más allá o más acá de tal acto resolutivo resultaría ajeno al drama" y por tanto, también al diálogo. 25

En el espacio narrativo, abierto entre el yo y el fin al que se aspira, se puede indicar en qué punto se está, al tener una representación del camino en su conjunto, aunque sea de una forma muy poco nítida. "Asir nuestras vidas en una narrativa" supone un modo de visión panorámica. ${ }^{26}$ Pero el espacio interpersonal dialó-

va, incluso a una solicitud venida de otro... Un compromiso que no fuera el de hacer algo que el otro pudiera escoger o preferir, podría no ser más que una apuesta estúpida” (MO, p. 292).

23 Op. cit., i. e. pp. 186, 204, 242, 291, 292.

${ }^{24} \mathrm{La}$ distinción entre dialéctico y dialógico se basa en dos fuentes principales: Szondi, P.: Teoría del drama moderno, pp. 79-82, donde se analizan las implicaciones que para el drama tiene la sustitución de la relación dialógica entre sujeto-objeto, por la confrontación entre ambos; y Balthasar, H.U.v.: Tl 1 , donde se aborda el "diálogo" como una forma de conocimiento opuesta en su raíz a la forma del "logos", sujeto a la discursividad e inclinada a apoyarse en un fundamento absoluto. Además, sobre la positividad de la diferencia dialógica: cf. Schindler, D. C.: Hans Urs von Balthasar and the Dramatic Structure of Truth. A philosophical investigation, Fordham University Press, New York, 2004, p. 38; también Ulrich, F.: Erzählter Sinn. Ontologie der Selbstwerdung in der Bilderwelt des Märchens, Freiburg, Johannes, 2000/2002, p. 417: “Aquí se da la paradoja de la afirmación de lo negado, -más allá de toda dialéctica. Las zonas límite no son en este sentido la definición periférica de un yo = yo indiferente que gira en torno a sí mismo, sino las rupturas y diferencias que reúnen en el drama del ser-con. Éstas lo garantizan verdaderamente" (p. 417). Sobre la estrecha relación entre el pensamiento de Balthasar y Ulrich, cf. Sara, J. M: Forma y Amor. Un estudio metafisico sobre la trilogía en Hans Urs von Balthasar, Kösel, Kempten, 2000, pp. 78-86.

25 Szondi, P.: Teoría del drama moderno, pp. 17, 80-81

26 Según Taylor, sólo en el "espacio moral" podemos decir quiénes somos gracias a que sabemos hacia dónde vamos y dónde estamos en ese camino. Este espacio es fundamentalmente narrativo: "determinamos lo que somos por lo que hemos llegado a ser, por la narración de cómo hemos llegado ahí" (FY, pp. 64, 65). Balthasar critica este punto de vista total al que se tiende en la narrativa: "la perspectividad de la verdad no es una perspectividad provisional que mediante una intensiva información, una especie de recorrido profundo en el campo de la verdad (como lo intentó Hegel en su Fenomenología del espiritu) pueda suprimirse y sintetizarse progresivamente en un punto de vista total” (Tl 1, p. 184). 
gico sugiere lo contrario: un espacio absoluto en el que, sin borrarse los límites entre yo y tú, la posición relativa no se puede calcular, es una cuestión que no admite graduación, porque espacio y tiempo se fundan en ese "ámbito intermedio". De ahí que no se pueda proyectar fuera de éste la sucesión de las acciones, pues el fin por el que se define el "recorrido" se encuentra en sí mismo; tampoco será posible entonces pensar en un tiempo distinto al presente 27.

La unidad y la diferencia simultáneas parecen por fin posibles en este ámbito dialógico, por eso será ahí donde la fidelidad pueda cumplir su función mediadora, pues ser fiel al sentido fundamental de la vida, supondrá ser fiel a sí mismo. Este espacio interpersonal surge de la mutua entrega, su sentido y fundamento no es otra cosa que el amor, que es sin fundamento, capaz de sostener simultáneamente la diferencia y la unidad entre dos. ${ }^{28}$ Es el único espacio en el que se puede realmente ser-con-otros, donde los límites necesarios de lo propio y lo ajeno, pierden su importancia 29 , donde lo sumamente importante, no es tanto la propia identidad, sino darse a quien se ama. El carácter relativo del diálogo humano -en tanto que relacional- no reduce su carácter absoluto, su relatividad queda trascendida en el amor, pero no sin recoger a las partes en diálogo. El sentido irrumpe en ese espacio con carácter absoluto, como algo que deja de depender del yo y del tú, y sin suprimirlos o relegarlos a algo accesorio, los mueve y atrae con una fuerza que no admite dilación, que puede mostrarse independiente de los deseos y aspiraciones personales, para abrirlos a algo que va más allá del tú y del yo, incluso del nosotros, dando una consistencia a lo personal que no podía proceder sólo de la relatividad de sus partes. Según Taylor "en la propia experiencia de ser movidos por un bien supremo, percibimos que lo que nos mueve es lo que de bueno hay en ello y no el que sea valioso a causa de nuestra reacción... Experimentamos hacia ello un amor bien fundamentado" 30 y las discriminaciones que esa "fuerte valoración" implica, "no reci-

27 Sobre el carácter absoluto del espacio dialogal, cf. Szondi, P.: Teoría del drama moderno, pp. 1721. "Lo interpersonal es absoluto en el drama porque junto a ese elemento no se registra la presencia ni de lo íntimo ni de lo ajeno al hombre" (op. cit., 81); "El lenguaje dramático está rigurosamente referido a la acción que discurre en un presente permanente" (op. cit., p. 87) y "la posibilidad del drama dependerá de la posibilidad del diálogo" (op. cit., 22).

28 "El hecho de que la comunicación no tenga lugar en virtud de otro fundamento que la comunicación misma, la caracteriza como amor" (Tl 1, p. 215). "El amor supone el uno, el otro y su unidad" (Balthasar, H. U. v.: "Intento de resumir mi pensamiento", en Communio, 1988, n 4, Julio-Agosto, p. 287). También cf. Guardini, R.: op. cit., p. 36 y Ulrich, op. cit., 416: "Die Liebe ist "vis concretiva"... einigende Macht, die dich mit dir selbst un dem Anderen zusammenwachsen lässt".

29 "El plano del sí y del otro puede ser trascendido: lo es en el amor... El amor gravita en torno a cierta posición que no es ni la del sí ni la del otro" (Marcel, G.: Ser y Tener, p. 154). "En tanto que vivo cualitativamente mis límites en fidelidad a mí mismo y a aquél que me deja ser (que soy yo, en tanto que liberadoramente me dejo y dejo ser a los otros, por tanto realizo mi ser como acto, no lo "tengo" como existencia muerta), los cumplo como los modos de la fecundidad de mi ser, hago emerger mi rostro en la aceptación de mí mismo, salgo expropiado del ocultamiento hacia el des-cubrimiento, vivo mi ser en verdad" (Ulrich, F.: Erzählter Sinn, p. 415).

${ }^{30}$ FY, p. 90. 
ben su validez de nuestros deseos, inclinaciones u opciones, sino que por el contrario se mantienen independientes de ellos y ofrecen los criterios por los que juzgarlos" (op. cit., p. 18). Un sentido absoluto aparece en medio de la finitud del marco (que se concreta principalmente en la limitación del tiempo y del espacio), cuando el individuo se vincula por medio de su acción a aquello que permanece más allá de sus preferencias y actos particulares, más allá del bien para mí. ${ }^{31}$ Este vínculo se constituye en lo esencial del yo, por eso allí donde los lazos se extienden de esta forma "infundada", se alcanza el sentido (la diferencia) y a la vez el yo (la unidad). Por otro lado, la única forma de hacer aparecer lo esencial, de que exista, es actualizándolo en su espacio, por eso ser yo es una cuestión ante todo de drama ${ }^{32}$, y la permanencia requiere un constante volver a su espacio y tiempo propios: al "aquí y ahora" del encuentro con el tú.

\subsection{El tiempo como aliado}

Cada momento en el espacio dialogal, supone el aquí y ahora de lo más importante, que sólo aparece y se realiza en la acción de entregarse, cualquiera que sea su forma. El valor único del momento, procede al mismo tiempo de su ahora o nunca, porque el fin tiene lugar en cada instante. "En el cada-caso-ahora de lo que acaba de hacerse presente tiene la aguda forma del en cada-caso-sólo-ahora... Esta caducidad es lo que confiere al instante su insustituible carácter valioso". 33 Sí, vendrán otras oportunidades, pero el amor no las conoce porque su tiempo es el presente. El amor, como el drama, ignora todo lo que ocurre fuera del espacio dialogal 34 .

Pero toda la importancia de este presente se torna clara sólo cuando consideramos su íntimo dinamismo como futuro y trascurrir temporal. La presencia se da como lo que siempre acaba de llegar. Es como el abrirse de una puerta, el entrar de una persona... esta propiedad de la respectiva presencia... es la futuridad inherente a ella (Tl 1, p. 192).

\footnotetext{
31 "Perhaps we could therefore describe the heart of dramatic action thus: a person commits himself in a decisive movement toward what he considers meaningful for him and sizes it. As the plot unfolds, and the layers of meaning are stropped away one by one, he finds that the meaning is, in fact, what has seized him. It is thus that drama affirms both the relative and the absolute at one and nonreductively" (Schindler, D. C.: Hans Urs von Balthasar and the Dramatic Structure of Truth, p. 320). Conviene recordar aquí la definición de drama dada por Balthasar: "acción de significado definitivo dentro de un marco finito" (Teodramática 4. La acción, Madrid, Encuentro, 1980/1995, p. 83).

32 No hay nada más dramático que esto: que lo más importante para la vida no se pueda asegurar con nada, "sino sólo ser concedido en libre antoentrega... [ahí] tiene su origen la dramática que se desarrolla entre libertades humanas" (Balthasar, H.U.v.: Epílogo, Madrid, Encuentro, 1987/1998, p. 64).

$33 \mathrm{Tl} 1$, p. 193

34 Szondi, P.: Teoría del drama moderno, p. 18.
} 
El pasado se caracteriza principalmente por su estar concluido, pero lo que hay que conservar no está en el pasado, sino en algo por realizar. La paradoja de que lo que hay que mantener esté a la vez por llegar, se comprende mejor si el valor del presente reside en su ser más que lo que aparece, en contener algo no concluido y así opuesto al pasado, una promesa de más en tanto que es siempre inicio ${ }^{35}$. El único "final" al que podría aspirar el amor es la renovación de la mutua entrega. Por eso la verdadera promesa de fidelidad que contiene el diálogo es la de mantener el amor ${ }^{36}$, lo cual no significa necesariamente no cambiar, y sí significa por el contrario apertura, novedad y esperanza de llegar a ese punto de inicio que supone siempre el sin porqué del amor. La fidelidad a lo propio, como renovación de lo esencial -el amor-, tendría que responder a dos de los aspectos básicos del mismo: su carácter irrevocable - porque no se deja someter a condiciones que pudieran alterarlo- $\mathrm{y}$ su carácter prometedor -porque el amor no tiene un máximo como meta, siempre implica un más, e imprime en cada cosa el ser más que lo que aparece-. En realidad, su irrevocabilidad coincide con su crecimiento 37 .

Así, tratándose fundamentalmente de amor, el tiempo no puede ir en contra, pues cada instante no es en primer lugar una pérdida de lo que se tenía hasta entonces, o bien un escalón más en el ascenso hacia el fin, sino la ocasión de ser, de responder al tú, de responsabilizarse de su situación dialógica, lo cual supone volver a lo esencial: la gratuidad del comunicar que a su vez se ha recibido. Por eso, aunque la "amenaza de la privación" nos incline a detenernos para asegurar así lo que somos, y aunque la "promesa" de hallar todavía lo esencial nos haga querer adelantar para llegar al final, se trata, si tenemos en cuenta la futuridad inherente al presente, de las máscaras con las que se presenta la fidelidad. "Yo sé -dice el amorque tú no eres aquel que representas" (op. cit., p. 209), el amor desenmascara porque sabe a qué se ha de ser fiel, no principalmente para lograr la propia unidad, sino para darse, que es la forma en que el amor permanece.

35 "El existir es esencialmente inacabado, más aún: es esencialmente comienzo, promesa, esperanza, brote; tiene la forma ontológica de lo que acaba de iniciarse... la dirección hacia el ser, y, por tanto, hacia ser más que lo que era en cada caso; por eso tiene carácter comparativo" (Tl 1, p. 192). "Si no comprendiera la dimensión del cada-vez-más, se le sustraería el verdadero sentido del presente, y su existir sería nulo, estaría entregado al pasado. No viviría ya mirando al principio, sino que estaría vuelto al final; en lugar de ir hacia lo abierto iría hacia lo cerrado, lo aislado, lo concluido; su presente mismo recibiría la forma del pasado" (op. cit., p. 194).

36 "Quizás en el plano ontológico la fidelidad es lo que más importa. En efecto, ésta es el reconocimiento... efectivo... de un permanente ontológico... y con relación al cual nosotros también duramos" (Marcel, G.: Ser y Tener, p. 111). Y más adelante dice: "El amor... en cuanto es ruptura de la tensión, que enlaza el mismo al otro, es, a mi modo de ver lo que podríamos llamar el dato ontológico esencial" (op. cit., p. 154).

37 Porque su mantenimiento consiste en volver a darse, en responder a su promesa de más (T1 1, pp. 193, 196). 
Nosotros vivimos... en una forma temporal que incluye tanto la promesa como la amenaza, y en la que esperanza y temor se mezclan ineludiblemente. Pero está en nuestras manos volvernos hacia el presente de modo tal que éste se torne progresivamente para nosotros comienzo de un eterno futuro, inclusive se torne presente de éste mismo... El pasado se mantiene en este presente sólo como una exhortación de aplicarnos con más seriedad que hasta el momento a lo que está por llegar, de no sustraernos a la decisión, de no retener posesión alguna (op. cit., p. 194).

Según lo dicho hay una especie de noble traición 38 en abandonar lo que se tiene entre manos si ello fuera necesario para volverse a ese futuro que llega en cada situación.

En el trasfondo de la inquietud por mantenerse fiel a las cosas estaría en última instancia la representación de que algo, con la debida paciencia, se podría quizá agotar. Precisamente la seriedad de la situación, que en cada caso se renueva y se modifica, es lo que nos impulsa a dejar a medio hacer la mayor parte de las cosas de la vida, a fin de volvernos reiteradamente a lo que hoy es más urgente... Se puede pasar de largo ante todo lo inesencial; a lo esencial hay que volver eternamente ${ }^{39}$.

\section{4. ¿Quién es Cressida? Hacia una identidad dramática}

Es tiempo de volver al drama del que partimos: Cressida es ahora fragmentos, porque los lazos del amor están deshechos y, sin vínculo, no hay posibilidad de unidad ni de ser. Lo esencial de sí misma ha dejado de actualizarse por falta de una respuesta personal que lo encarnase. Se requería responsabilidad por parte ambos, hacerse cargo del propio ser que en un momento dado se expresó con palabras y se dio con ellas:

Troilo - Escúchame amor mío. Solamente te encargo que seas fiel de corazón... Cressida - ¡Yo, fiel! ¡Cómo! ¿Qué perversa suposición es esa?... Seré fiel40.

\footnotetext{
38 El término está tomado de un texto de Nietzsche, recogido en la Antología que Balthasar publicó sobre él: "Von Feuer erlöst, schreiten wir dann, durch den Geist getrieben, von Meinung zu Meinung, durch den Wechsel der Parteien, als edle Verräter aller Dinge, die überhaupt verraten werden können, -und dennoch ohne Gefühl von Schuld" (Nietzsche, F.: Antologien, Auswahl Hans Werner -pseudónimo de H.U.v. Balthasar, en la época de dominio nazi-, Freiburg, Johannes Verlag Einsiedeln, 2000, p. 219; el texto original se encuentra en: Kritische Studien Ausgabe 2 (KSA 2), dtv München, Gruyter, 1988, p. 362).

$39 \mathrm{Tl} 1$, p. 196.

40 Shakespeare, W.: Troilo y Cressida, pp. 598 y 599.
} 
La perversidad a la que Troilo se anticipa es la de poder negar e invertir los lazos, la de vulnerar la fortaleza de la confianza, sólo sostenida sobre un amor que está expuesto a lo perverso, pero cuya vulnerabilidad no es más que la consecuencia de ser lo último, porque debajo del amor no hay nada. Todo lo sublime participa de algún modo de esta posibilidad de perversión, porque si estuviera asegurado por algo distinto al «débil» amor, perdería su valor y fortaleza. Con su acción, Cressida no dio testimonio de sus palabras, rompiendo así el espacio y el tiempo del diálogo, destruyendo lo construido en él y sus posibilidades, todas las promesas que cada instante de aquel presente contenía.

Cressida es ahora alguien distinto, y para Troilo, es más fácil aceptar que hay dos Cressidas que Cressida esté dividida. Ésta puede bien ser aquí el nombre dado al amor, esencialmente indivisible, por eso se pueden admitir mejor dos verdades contrarias que la ruptura de Cressida. La locura de la lógica, que puede defender el pro y el contra de la misma causa radica en que "la verdad admite una fragmentación que el amor no puede resistir" 41 . A los ojos del amante, ella tiene que permanecer siendo ella para que todo tenga un sentido y sea posible una ley en la identidad misma. Si los lazos se deshacen, el sentido desaparece, y los lazos, cuando se trata de hacer aparecer lo esencial, son drama, acciones dramáticas que actualizan el amor -hacen presente y ponen en juego ${ }^{42}$ y con él, "el uno, el otro y su unidad"43. Esa actualización supone una novedad necesaria para ser uno mismo, por eso el drama, no es accesorio: "agere sequitur esse exige al mismo tiempo un esse sequitur agere. No es necesario desarrollar esta verdad desde un punto de vista filosófico, pues es ya evidente desde un punto de vista 'dramático"'44. El yo tiene aún que ser, por eso necesita actualizar su papel para poder ser él mismo. En la fidelidad al papel, donde se recoge el aquí y ahora que el diálogo dispone, se encuentra el yo consigo mismo. Se trata de una unidad misteriosa, porque está llena de distancia, como la que hallamos en el actor que logra la unidad dramática con su personaje. La identidad personal se levanta sobre la diferencia, yo y papel sólo son uno en el drama, por eso sólo en el drama hay identidad.

Finalmente, ¿existe algún modo de retornar, de reconstruir, se puede reparar la rasgadura de los lazos y reconfigurar así la unidad y el ser? ¿Es posible realmente toda esta cadena de res? Si seguimos la misma lógica que hasta ahora-locura de la lógica-, no puede haber nada concluido para siempre, ningún «pasado» inamovible,

\footnotetext{
$41 \mathrm{Tl} 1$, p. 127.

42 Sobre lo que actuar implica en el drama, puede verse Abirached, R.: La crisis del personaje moderno, pp. 72-74 y Balthasar, H.U.v.: Td 1, pp. 271-275. En ambos aparece la idea de "hacer presente" y de "jugar", con el aspecto de "gratuidad" que ello implica.

43 Ver nota 26.

$44 \mathrm{Td} 2$, p. 15. De forma similar se expresa Blondel: "Nosotros no somos, no conocemos, no vivimos más que sub specie actionis... No solamente la acción manifiesta lo que ya éramos sino que también nos hace crecer y, por así decirlo, salir de nosotros mismos" (Blondel, M.: La Acción, p. 236).
} 
porque resulta imposible suprimir el más del amor cuando éste sí permanece. Sin embargo, la apertura y el futuro quedan entonces a merced de la posibilidad, quizá remota, de un amor más fuerte capaz de curar la herida mortal que supone la fractura. Concluimos así, con las preguntas con las que nos deja el silencio, como aquel que queda entre la caída del telón y el aplauso, cuando uno se hace cargo por primera vez de lo visto y oído en el escenario. Y con el final y el silencio de cada obra, se da paso a la vida, a la respuesta personal acerca de algo que no puede resolverse sino en el «aquí y ahora» del teatro del mundo.

\section{Bibliografía}

ABIRACHED, R.: La crisis del personaje moderno, trad. B. Ortiz de Gondra, Madrid, Publicaciones de la asociación de directores de escena, 1978/1994.

Balthasar, H. U. v.: Epilogo, trad. I. Murillo, Madrid, Encuentro, 1987/1998.

Balthasar, H. U. v.: "Intento de resumir mi pensamiento", trad. J. M. Oriol y F. Hernández, en Communio, 1988, nº 4, Julio-Agosto, pp. 284-288.

Balthasar, H. U. v.: Teodramática 1: Prolegómenos, trad. E. Bueno de la Fuente y J. Camarero, Madrid, Encuentro, 1973/1990 (= Td 1).

BalthasaR, H. U. v.: Teodramática 2: Las personas del drama: el hombre en Dios, trad. E. Bueno de la Fuente y J. Camarero Madrid, Encuentro, 1976/1992 (= Td 2).

Balthasar, H. U. v.: Teodramática 4: La Acción, trad. E. Bueno de la Fuente y J. Camarero, Madrid, Encuentro, 1980/1995.

Balthasar, H. U. v.: Teológica 1: Verdad del Mundo, trad. L. Piossek y J. P. Tosaus, Madrid, Encuentro, 1985/1997 (= Tl 1).

Blondel, M.: La Acción, trad. J. M. Isasi y C. Izquierdo, Madrid, B.A.C., $1893 / 1996$.

Buber, M.: Yo y Tú, trad. Carlos Díaz, Madrid, Caparrós, 1923/1998.

CRITES, S.: "Storytime: Recollecting the Past and Projecting the Future", en T. R. Sarbin (ed.), Narrative Psychology: The Storied Nature of Human Conduct, Nueva York, Praeger, 1986, pp. 152-173.

GERGEn, K. J.: El yo saturado. Dilemas de identidad en el mundo contemporáneo, trad. L. Wolfson, Barcelona, Paidós, 1991/1992.

GuARDINI, R.: La aceptación de sí mismo, trad. J. M. Valverde, Madrid, Ediciones Cristiandad, 1960/1970.

LyOTARD, J-F.: La condición postmoderna, trad. M. Antolín Rato, Madrid, Cátedra, 1984/2004.

MARCEL, G.: Ser y Tener, trad. A. M. Sánchez López, Madrid, Caparrós, 1935/2003. 
NiEtzsche, F.: Antologien. Auswahl Hans Werner (pseudónimo de H.U.v.B, en la época de dominio nazi), Freiburg, Johannes Verlag Einsiedeln, 2000, p. 219. Texto original en: Kritische Studien Ausgabe 2 (KSA 2), dtv München, Gruyter, 1988, p. 362.

PARfit, D.: Reasons and Persons, Oxford, Clarendon Press, 1984.

PAVIS, P.: Diccionario del teatro. Dramaturgia, estética, semiología, trad. J. Melendres, Barcelona, Paidós, 1996/1998.

Ricoeur, P.: Sí mismo como otro, trad. A. Neira Calvo, Madrid, Siglo XXI, 1990/1996.

Rodríguez GonzÁlez, M.: El problema de la identidad personal. Más que fragmentos, Madrid, Biblioteca Nueva, 2003.

SARA, J. M.: Forma y Amor. Un estudio metafísico sobre la trilogía en Hans Urs von Balthasar, Kösel, Kempten, 2000.

SCHINDLER, D. C.: Hans Urs von Balthasar and the Dramatic Structure of Truth. A philosophical investigation, Fordham University Press, New York, 2004.

Szond, P.: Teoría del drama moderno. Una tentativa sobre lo trágico, trad. J. Orduña, Barcelona, Destino, (1956/1961)/1994.

TAYlor, Ch.: Fuentes del yo. La construcción de la identidad moderna, trad. A. Lizón, Barcelona, Paidós, 1989/1996.

Ulrich, F.: Erzählter Sinn. Ontologie der Selbstwerdung in der Bilderwelt des Märchens, Freiburg, Johannes, 2000/2002.

Velleman, J. D.: “The Self as Narrator", Self to Self, Nueva York, Cambridge University Press, 2006, pp. 203-223.

Ana Álvarez Garrido

Universidad Complutense de Madrid

Departamento de Filosofía IV

Teoría del Conocimiento e Historia del Pensamiento

a_alvarez_g@hotmail.com 